\title{
STRESS AND AGE AS PREDICTORS OF POOR FAMILY RELATIONS AMONG FEMALE HEALTHCARE PROFESSIONALS
}

\author{
Nazia Mustafa, Tahir Sardar*, Najm Us Saqib Khan**, Muhammad Naveed Akhtar*, Javaria Mumtaz ${ }^{* * *}$, \\ Usama Bin Zubair****
}

General Headquarter, Rawalpindi Pakistan, *Army Medical College/National University of Medical Sciences (NUMS) Rawalpindi Pakistan, ${ }^{* *}$ Naval Headquarter Islamabad Pakistan, ${ }^{* * *}$ Tehsil Headquarter Hospital, Arifwala Pakistan, ${ }^{* * * * P a k}$ Emirates Military Hospital/National University of Medical Sciences (NUMS) Rawalpindi Pakistan

\begin{abstract}
Objective: To investigate the role of stress and age in managing family relations.

Study Design: Cross sectional study.

Place and Duration of Study: Public sector hospitals in Rawalpindi and Islamabad, from May 2018 to Jun 2018.

Methodology: A sample of 103 females healthcare professionals (Doctors=15, Psychiatrists=14, psychologists=29, Nurses $=22$ and others=23) (Married=53, unmarried=50) with mean age of 30 years (range from 20 to 50 years) were taken from various hospitals in Rawalpindi and Islamabad. Data was collected by using the perceived stress scale and the index of family relations.

Results: Results revealed significant positive correlation between age and poor family relations whereas correlation between stress and family relations is not significant. Regression analysis showed age as predictor of poor family relations. These findings were interpreted with the support of literature.

Conclusion: It is concluded a work- family life balance should be achieved and presence of stress or mental health problems should be screened timely in order to manage them before it's too late.
\end{abstract}

Keywords: Daily life stress, Family relations, Healthcare professionals.

This is an Open Access article distributed under the terms of the Creative Commons Attribution License (http://creativecommons.org/licenses/by/4.0), which permits unrestricted use, distribution, and reproduction in any medium, provided the original work is properly cited.

\section{INTRODUCTION}

Relationships and families play vital role in human's life. They provide people with both joys and challenges. They help individuals to learn, to manage stress, to understand emotions and behaviors and to communicate effectively ${ }^{1}$. These all aspects remain important throughout life span of any individual but its importance is specially highlighted in adult life when individual has to manage both family and work life. Though, it is challenging for both men and women but due to our specific cultural and religious background, this responsibility comes more on shoulder of female members of the family.

There are different factors at work setting those can interfere with family relations such as job pressure, role conflict and ambiguity, and a heavy workload are related to poor family relations ${ }^{2}$. Work orientations such as involvement

Correspondence: Dr Nazia Mumtaz, Flat \# C, Block E-15, General Javed Sultan Shaheed Colony, Convoy Road, Rawalpindi Pakistan Received: 22 Dec 2020; revised received: 06 Jan 2021; accepted: 10 Jan 2021 and commitment also reveal negative relationships with family involvement ${ }^{3}$. Specially, there are certain professions which required more time, commitment and involvement such as health care professionals who are constantly available to others in case of any emergency phase. They are mostly personnel from rescue services, military, healthcare departments and certain sections of social services ${ }^{4,5}$. Their work is extremely challenging and they themselves at risk ${ }^{6,7}$ for the development of stress related issues over the period of time. Specially, those you have multiple responsibilities other than work are more prone for such issues ${ }^{8,9}$.

Work life balance of healthcare professional is very important for their smooth functioning and studied throughout the world. Doctors in training in the UK from the perspectives of trainers and trainees was investigated by Rich et al. They concluded that trainee doctors regularly moved workplaces which could disrupt their personal lives and sometimes led to separation from 
friends and family ${ }^{10}$. Work-life imbalance was particularly severe for those with children and especially women who faced a lack of less-thanfull-time positions and discriminatory attitudes. Female health care workers frequently talked about having to choose a specialty they felt was more conducive to a work-life balance such as General Practice. This clearly showed that female health workers are more at risk of having poor family relations due to stress of never adjusting work-life balance. So present study was planned with aim to investigate the role of stress and age in managing family relations among these female healthcare professionals.

\section{METHODOLOGY}

A sample of 103 females healthcare professionals (Doctors=15, Psychiatrists=14, psychologists $=29$, Nurses $=22$ and Others $=23)($ Married $=53$, Unmarried $=50$ ) with mean age of 30 years (range from 20 to 50years) were taken from various hospitals in Rawalpindi and Islamabad. After having their verbal consent for the participation, written inform consent was given to them. This Inform consent comprised of brief introduction of research topic, its importance and purpose, confidentiality and their right to withdraw at any stage of research).

Afterwards questionnaires which includes demographic form, Perceived Stress Scale (PSS) and Index of Family Relations (IFR) were provided to healthcare professionals. The Perceived Stress Scale (PSS) is the most widely used psychological instrument for measuring the perception of stress. It is a measure of the degree to which situations in one's life are appraised as stressful. Items were designed to tap how unpredictable, uncontrollable, and overloaded respondents find their lives. The scale also includes a number of direct queries about current levels of experienced stress $^{11}$. Index of Family Relations (IFR) measures the degree, severity, or magnitude of the problem that family members perceive in their relationship and hasreliability alpha is 0.95 . It comprises of 25 items, each of which is scored according to following five categories. ' 1 ' as none of the time,
' 2 ' as a little of the time, ' 3 ' as all of the time, ' 4 ' as a good part of the time and ' 5 ' as all the time. Some of the items are positively worded statements while others are negatively worded to control response set biases. The IFR produces a score ranging from 25 to 125 where a low score indicates the relative absence of the problem being measured, and a higher score indicates the presence of a more severe problem. Reverse scoring has been assigned to following items (Positively worded items); 1,2,4,5,8,14,17,18,20,21 and 23 . The negatively worded items scored in normal way. High scores on it indicated poor family relations ${ }^{12,13}$.

The participants were asked to read each statement carefully and give their responses by selecting the response category which they considered appropriate. They were acknowledged for their participation and cooperation. The data was entered on SPSS-20 and analyzed. Descriptive Statistics were carried out to describe the mean, $\mathrm{SD}$, frequencies and reliability coefficients. Person Correlation and Regression was used to see the relationship between different variables.

\section{RESULTS}

Results revealed that age of participants was between range of 30 years (range from 20 to 50 years) further, perceived stress scale $(\mathrm{r}=0.67)$ and index of family relations (IFR) $(\mathrm{r}=0.83)$ were reliable.

Table-II shows the of alpha coefficients of the Perceived Stress Scale (PSS) and Index of Family Relations (IFR). The reliabilities of both the scales are good.

Table-III shows the correlation coefficients of perceived stress and agewith family relations. Results revealed that age is significantly positively correlated with family relations whereas correlation between perceived stressand family relations is not significant.

Simple linear regression analysis of perceived stress, age and family relations.

A prediction was also made that perceived stress andage will be an important predictor of 
family relations among female health care professionals. To verify this prediction simple linear regression was carried out ${ }^{14}$.

Table-I: Means and standard deviations of different variables $(\mathbf{n}=\mathbf{1 0 3})$.

\begin{tabular}{l|c}
\hline Variables & Mean \pm SD \\
\hline Perceived Stress & $25.53 \pm 6.83$ \\
\hline Family Relations & $64.56 \pm 18.64$ \\
\hline Age & $30.12 \pm 6.41$ \\
\hline
\end{tabular}

Table-II: Alpha reliability coefficients of the Perceived Stress Scale (PSS) and Index of Family Relations (IFR) (n=103).

\begin{tabular}{l|c|c}
\hline Subscales / Composite & $\begin{array}{c}\text { No. of } \\
\text { Items }\end{array}$ & $\begin{array}{c}\text { Alpha } \\
\text { Coefficients }\end{array}$ \\
\hline Perceived Stress Scale & 14 & 0.67 \\
Index of Family Relations & 25 & 0.83 \\
\hline
\end{tabular}

Table-III: Correlation coefficients of perceived stress with family relations $(n=103)$.

\begin{tabular}{l|c}
\hline Variables & Family Relations \\
\hline Perceived Stress & 0.21 \\
\hline Age & $0.40^{*}$ \\
\hline${ }^{*} b<0.01$ &
\end{tabular}

Table-IV exhibits the proportion of variance by age on family relation problems. The results revealed that age significantly predicts family relation problems among female healthcare professionals.

Table-V exhibits the proportion of variance by perceived stress on family relation problems. The results revealed that perceived stress does not significantly predict family relation problems among female healthcare professionals. this responsibility comes more on shoulder of female members of the family. Situation becomes difficult and intense when women have to cater for dual responsibility i-e manage both family life and work life. Therefore, sometime it is hard for the working women to cope with the challenges of life as compared to housewives. Medicine is a demanding profession which involves the responsibility of lives of people. All the health care professionals may it be doctors or nurses have tough work life with regard to nature of duty and working hours. Things become grave when they have responsibility of home and family as well. We planned this study with the rationale to investigate the role of stress and age in managing family relations by female health care professionals.

Thomas et al in 2017 published an interesting paper emphasizing on the fact that relationships with family members are significant for wellbeing across the whole life course of human beings ${ }^{15}$. As individuals age, family relationships often become more complex, with sometimes complicated marital histories, varying relationships with children, competing time pressures, and obligations for care. Stress process theory suggests that the positive and negative aspects of relationships can have a large impact on the wellbeing of individuals. Our study supported their stance in the sense that significant positive cor-

Table-IV: Simple linear regression analysis between age andfamily relations.

\begin{tabular}{l|c|c|c|c|c}
\hline Variables & B & SE & Beta & t & F \\
\hline Constant & 30.01 & 8.009 & & 3.747 & - \\
\hline Age & 1.154 & 0.260 & 0.405 & 4.435 & 19.670 \\
\hline
\end{tabular}

R2=0.40; $\Delta \mathrm{R} 2=.16 ;{ }^{* * *} p<0.001$

Table-V: Simple linear regression analysis between perceived stress and family relations.

\begin{tabular}{l|c|c|c|c|c}
\hline Variables & B & SE & Beta & t & F \\
\hline Constant & 56.431 & 6.968 & - & 8.099 & - \\
\hline VT & 0.329 & 0.267 & 0.123 & 1.236 & 1.52 \\
\hline R2 $=0.123 ; \Delta \mathrm{R} 2=0.015 ; * * *<0.001$ &
\end{tabular}

\section{DISCUSSION}

Family life is of utmost importance in making one's life smooth and satisfactory. It is responsibility of all the units of family to work and take part in keeping the family intact and happy but due to cultural and religious factors relation existed between age and poor family relations in our study participants whereas correlation between stress and family relations was not significant.

Stewart et al in 2000 (Stewart, 2000) performed a study to determine perceptions of their 
health, stress, satisfaction, knowledge, and abuse rates in medical practice. They concluded that family physicians were more likely to be divorced or separated highlighting the poor family functioning. These women may have had to face leading to their divorce and separation ${ }^{16}$. We highlighted similar aspect among the female health care professionals. Though we did not look for the relationship of specialized field or job description but our findings involved all the female health care professionals mention in our inclusion criteria. Resilience, burn out and coping mechanisms among doctor working in United Kingdom were studied by Mckinley et al in 2020. They concluded that doctors had less resilience score as compared to non-doctor population. High level of burn out and stress was also found in their target population. Stress was the main finding in our target population ${ }^{17}$. But it was not significantly interfering with their family relations as compared to females across the globe. This is because of the fact that Pakistani women are more resilient as they have to face stressful events throughout their life. But with age, their coping resources get decline, and they started get effected. Relationship of women well-being and family function has been well established ${ }^{18}$.

This is usually a bi-modal relationship and change in one parameter definitely affect the other. Results of our study also lay emphasis on it that female health workers if stressed or burnt out may endanger their family life and compromised family life can affect their work and overall quality of life. Therefore, a work-life balance should be achieved and presence of stress or mental health problems should be screened timely in order to manage them before it's too late.

\section{CONFLICT OF INTEREST}

This study has no conflict of interest to be declared by any author.

\section{REFERENCES}

1. American Psychiatric Association. Diagnostic and Statistical Manual for mental disorders. ( $4^{\text {th }}$ ed). Washington. DC. 2000.

2. Voydanoff P. Incorporating community into work and family research: A review of basic relationships. Human Relations 2001; 54(12): 1547-72.

3. Greenhaus JH, Parasuraman S. Research on work, family, and gender: Current status and future directions. In G. N. Powell (Ed.). Handbook of gender and work. Thousand Oaks, CA: Sage 1999.

4. Niaz U. Pakistan Earthquake 2005: The Day the Mountains Moved. Sama Editorial and Publishing services. 2005.

5. Alexander DA, Klein S. First responders after disasters: A review of stress reactions, at-risk, vulnerability, and resilience factors. Prehospital Disast Med 2009; 24(2): 87-94.

6. Berah EF, Jones HJ, Valent P. The experience of mental health team involved in early phase of disaster. Australia News Land J Psychiatr 1984; 18(1): 354-58.

7. Riaz A. The relationship of coping strategies with family relations among adolescents. Msc Dissertation. NIP. QAU. 2000.

8. Briere J, Scott C. Principle of trauma therapy: A guide to symptoms, evolution and treatment. Sage publication Inc: India. 2006.

9. Gadit A. Disaster, mental health and rescuing medical Professionals. J Ayub Med Coll Abbottabad 2005; 17(4): 1-9.

10. Rich A, Viney R, Needleman S, Griffin A, Woolf K. You can't be a person and a doctor: the work-life balance of doctors in training - a qualitative study. Br Med J Open 2016; 6(12): e013897.

11. Cohen S, Kamarck T, Mermelstein R. A global measure of perceived stress. J Health Social Behav 1983; 24(1): 386-96. Available from:https://www.northottawawellnessfoundation.org/ wpcontent/uploads/2018/04/PerceivedStressScale.pdf

12. Tutty LM. Theoretical and practical issues in selecting a measure of family functioning. Research on Social Work Practice 1995; 5(1): 80-106.

13. Khurshid M, Rehman G. Impact of peer relations on the selfesteem of juvenile delinquents. J Pak Psychiatr Soc 2006; 3(2): 78-82.

14. Cohen J, Cohen P. Applied multiple regression analysis for behavioral sciences. (2nd Ed.). Hillsdale: Lawrence Erlbaum. 1983.

15. Thomas PA, Liu H, Umberson D. Family Relationships and Well-Being. Innovation Aging 2017; 1(3): igx025.

16. Stewart DE, Ahmad F, Cheung AM, Bergman B, Dell DL. Women physicians and stress. J Wom Health Gend Base Med 2000; 9(2): 185-90.

17. McKinley N, McCain RS, Convie L, Clarke M, Dempster M, Campbell WJ, et al. Resilience, burnout and coping mechanisms in UK doctors: a cross-sectional study. Br Med J Open 2020; 10(1): e031765.

18. Farajzadegan Z, Koosha P, Sufi GJ, Keshvari M. The relationship between family function and women's well-being. Iran J Nurs Midwifery Res 2013; 18(1): 9-13. 